\title{
Reimagining Community Relationships for Organizational Learning: a Scoping Review With Implications for a Learning Health System
}

Crystal Milligan ( $\nabla$ crystal.milligan@mail.utoronto.ca )

University of Toronto Dalla Lana School of Public Health https://orcid.org/0000-0001-5413-3800

Dorothy Wong

University of Toronto Institute of Health Policy, Management and Evaluation

Whitney Berta

University of Toronto Institute of Health Policy, Management and Evaluation

Research article

Keywords: Learning health system, organizational learning, learning organization, community

Posted Date: December 29th, 2020

DOI: https://doi.org/10.21203/rs.3.rs-135727/v1

License: (1) (1) This work is licensed under a Creative Commons Attribution 4.0 International License.

Read Full License 


\section{Abstract}

Background: Communities represent a highly relevant source of knowledge with regard to not only healthcare performance but also sociocultural context, yet their role in learning health systems has not been studied. Situating the learning health system as an organization, this paper explores the phenomenon of organizational learning from or with communities (defined as one of 'the people,' such as a town, a specific patient group or another group directly receiving a healthcare service).

Methods: We conducted a scoping review to determine what is known about organizational learning from or with communities that the organization serves, and to contribute to a more comprehensive evidence base for building and operating learning health systems. In March 2019, we systematically searched six academic databases and grey literature, applying no date limits, for English language materials that described organizational learning in relation to knowledge transfer between an organization and a community. Numerous variables were charted in Excel and synthesized using frequencies and thematic analysis. We updated this search in August 2020.

Results: In total, 42 documents were included in our analysis. We found a disproportionate emphasis on learning explicit knowledge from community rather than on tacit knowledge or learning in equal partnership with community. Our review also revealed inconsistently defined concepts, tenuously linked with their theoretical and empirical foundations. Our findings provide insight to understand the organization-community learning relationship, including motives and power differentials; types of knowledge to be learned; structures and processes for learning; and transformative learning outcomes.

Conclusions: Our review makes a singular contribution to organizational learning literatures by drawing from diverse research disciplines such as health services, business and education to map what is known about learning from or with community. Broadly speaking, learning health systems literature would benefit from additional research and theory-building within a sociological paradigm so as to establish key concepts and associations to understand the nature of learning with community, as well as the practices that make it happen.

\section{Background}

Since it was first proposed over a decade ago, the concept of a learning health system has inspired health systems researchers and practitioners around the world [1]. Common sense tells us that a continuously improving health system-one that generates, shares and learns from new evidence on an ongoing basis -is a good thing. However, the study of learning health systems has generally not been systematic, resulting in a variously defined concept whose hallmark characteristics are poorly articulated.

Researchers who have taken more systematic approaches to conceptualizing learning health systems suggest that it is questionable whether more than a handful of learning health systems genuinely exist, if any [2-4]. 
We sought to contribute to a more comprehensive evidence base for building and operating learning health systems, drawing from health services research and other research disciplines including the organization sciences, business, and education. We started with the premise that healthcare systems are socially constructed through processes involving numerous stakeholders [5]. As external, extraorganizational processes of social learning and construction are generally understudied with regard to learning health systems, we chose to focus our study on the processes and role relating to a particular type of health system stakeholder: the community (or communities) that health systems serve. We broadly defined 'community' as one of 'the people'-such as a town, a specific healthcare patient group or another group directly receiving a healthcare service-not a professional community of practice. We saw this study as a means to enhance our understanding of learning health systems as organizations and to explore their critical system-developmental relationships beyond traditionally defined healthcare system borders.

While there are numerous studies of organizational learning from other organizations and networks in the external environment [e.g., 6, 7-10], there are seemingly few studies of organizational learning from or with communities. Though the rhetoric of community engagement and partnership may be strong in healthcare-take calls for patient involvement, for instance-there is a tendency to refer to organizational learning from these interactions in the abstract [11]. This obscures our understanding of the motives, structures, processes and outcomes of organizational learning generally, and specifically from or with communities. In fact, community relationships represent the least researched dimension of relationshipcentred healthcare [12].

As a starting point, we conceptualized learning health systems as organizations that are complex adaptive systems, intrinsically connected with their internal and external environments. In this view, system behaviour and learning are generated by complex interactions and relationships among the system's constituent parts and internal or external agents $[13,14]$. Critical to enabling these interactions and relationships is what complexity science theorists call adaptive space, which is described as temporary network structures that open channels of communication such that diverse ideas can mix and learning can emerge [15]. It follows that community knowledge from the external environment can contribute to organizational learning provided the structures and relations of power within adaptive space permit that knowledge to be valued and integrated.

Organizational learning theory supports the complexity science view that the external environment has bearing on organizational learning. In a seminal article, March [16] described organizational learning as adaptation informed by exploitation and exploration-a dual strategy of not only applying knowledge that is already familiar, but also exploring the external environment for new knowledge. In their descriptions of social theories of learning and the context-dependent nature of knowledge, many of March's contemporaries similarly emphasized the importance of bridging organizational and environmental levels of analysis [17-20]. 
Perhaps surprisingly then, when it comes to exploring learning phenomena in healthcare and other industries, the organization's relationships with the communities it serves seem to be overlooked. Learning health systems literature disproportionately emphasizes electronic health records and other information technology [21,22], thus privileging the transmission of quantified, explicit knowledge and sidelining tacit understandings of sociocultural factors that are equally important to improve healthcare services. Such a narrow orientation toward clinical research and health service data neither adequately captures the breadth and depth of relevant theory from other research traditions, nor promotes a model that gives credence to non-clinical or tacit forms of knowledge.

\section{Study aim}

Our study contributes to addressing this gap. The community represents a source of knowledge with regard to healthcare performance at organizational and whole system levels, as well as tacit culture, identity and ideology. Part of the operating environment, the community also represents a social context in which the healthcare organization is embedded, including established norms and worldviews that the organization must navigate in order to benefit the community at individual and collective levels.

Specifically, we aimed to determine what is known in extant literatures about organizational learning from or with community so as to shed light on the learning health system as an organization in the context of its social relationships and interactions with the external environment. In this paper, we present the results of our study and then discuss key implications and gaps with regard to our understanding and implementation of learning health systems.

\section{Theoretical roots}

As there are many excellent reviews of the origins and evolution of organizational learning scholarship [23-27], we limit ourselves here to a brief background of concepts most relevant to this study.

Argyris and Schön $[28,29]$ described organizational learning as a process of error correction via singleloop or double-loop learning, where double-loop learning goes beyond simply solving a problem to changing underlying assumptions or values that may alter future behaviour. They proposed that individual learning embeds within organizational memory and thus can lead to organizational changes and performance improvement. Similarly, Huber [30] suggested that organizational learning comprises knowledge acquisition, information distribution, information interpretation and organizational memory, frequently resulting in a change in the nature and range of the organization's potential behaviours.

Tension between individual and collective initiatives, including learning, is a regular feature of organizational learning literatures across research disciplines. The rise of social theories of learning in the 1990s led to a more collective-oriented ontology of organizational learning that was less dependent on individual learning as its source [e.g., 17, 19]. The natural resource management sciences, in particular, embrace the concept of social learning. Drawing from social theories that characterize learning as active social interaction and participation [17,31], social learning is defined as "a change in understanding that goes beyond the individual to become situated within wider social units" [32]. In our interpretation, 
organizations count as 'wider social units' given that they are social entities-albeit coordinated in a hierarchical fashion. Yet again, the 'change in understanding' is frequently clarified with transformative learning theory [33], a body of theory initially focused on individual learning but regularly applied to explain the transformation of assumptions and worldviews that comes with second-order, or double-loop, learning [32, 34].

We view the learning health system as a kind of learning organization. The learning organization concept originates in work by Argyris and Schön $[28,29]$ but was popularized by Senge [35] in North America and Burgoyne, Pedler and Boydell [36] in the United Kingdom. Senge [35] defined the learning organization as one with both adaptive (single-loop) and generative (double-loop) learning capacities built on individual, collective and organizational learning processes. Notably, the learning organization is not equivalent to organizational learning. Many authors describe organizational learning and the learning organization as the process and product, respectively -a normative distinction between what is done and what should be [37-39]. Others have suggested that the two concepts are developing along divergent tracks, with learning organization theorists pulling concepts from organizational learning, but not the other way around [25]. Meanwhile, scholars highlight a lack of consensus in the way organizational learning and learning organizations are described, with authors often confusing process with outcome [40] or failing to recognize how different worldviews may pre-determine how organizational learning is conceptualized within different research disciplines [27].

In this review, we subscribe to a conceptualization of the learning organization that combines three elements: organizational knowledge, including internal and external knowledge; knowledge management, or the control of structures and processes to facilitate knowledge sharing; and organizational learning processes $[37,41]$.

\section{Methods}

A scoping review was well-suited to our aim given that we sought to map concepts across interdisciplinary boundaries and provide a broad overview of the range of current evidence, including gaps in research [42]. Following established methodology [43-45], this review contributes to an expanded view of organizational learning and its key concepts, offering guidance to deepen our understanding of the relationship between learning health systems and the learning that takes place with and from communities they serve.

\section{Search strategy}

We consulted a health sciences librarian in planning and developing our review design and search strategy. Our comprehensive search strategy included an academic database search, hand searching of relevant journals, search engine queries, targeted website review and reference tracking. We based our search on three concepts: organizational learning, including social learning; the learning organization, comprising organizational learning, organizational knowledge and knowledge management and 
including learning health systems; and community, comprising community knowledge and involvement. The search protocol is registered and available with the Open Science Framework (hyperlink removed for double-blind review).

We first conducted an initial search in Scopus to identify journals with the highest number of relevant publications, then searched an online global directory [46] to locate databases where these journals were indexed. The initial academic search strategy was developed for Ovid MEDLINE® (see appendix) and then translated for other academic databases. Several preliminary, iterative searches permitted us to refine a search using a combination of subject headings and text words for the three primary concepts, and tailor our strategy to each database. Final searches with no language or date limits were conducted on March 19, 2019 in Ovid MEDLINE® (1946-Present), PsycINFO (1806 to March Week 2 2019), CINAHL Plus with Full Text, ERIC, Web of Science Core Collection and Business Source Premier. To supplement the academic database search, the lead author hand searched all issues of two journals, The Learning Organization and Learning Health Systems, finding 11 potentially eligible citations.

Table 1

Summary of search locations

\begin{tabular}{|ll|}
\hline Academic databases & Online search engines \\
\hline - Ovid MEDLINE $®$ & - Advanced Google Search \\
• PsycINFO & - Duck Duck Go \\
• CINAHL Plus & Targeted websites \\
- ERIC & - Agency for Healthcare Research and Quality \\
- Web of Science & (ahrq.gov) \\
- Business Source Premier & - McMaster Health Forum (mcmasterforum.org) \\
Hand searched journals & - National Academy of Medicine (nam.edu) \\
- The Learning Organization & - The Learning Healthcare Project \\
- Learning Health Systems & (learninghealthcareproject.org) \\
Reference tracking & \\
- Reviewed reference list of 1 evidence & \\
synthesis report & \\
\hline
\end{tabular}

We also searched online, using numerous combinations of key terms in Advanced Google Search and Duck Duck Go. The lead author reviewed search results up to five webpages after the last hit and found ten potentially eligible citations. Websites of four organizations well known for their contributions to the study of learning health systems were also reviewed, finding three potentially eligible citations by browsing and searching for publications on these sites. When multiple publications were available as 
part of a series, the most recent or summative publication was chosen. In the case of one evidence synthesis publication found in this way, the lead author found ten additional potentially eligible citations through reference tracking. Table 1 lists all the information sources that we searched. All potentially eligible citations were loaded into EndNote X9.1.1 for deduplication [47].

\section{Eligibility criteria}

We sought to identify work based in empirical research, theory or experience that described organizational-level learning, change or innovation in relation to knowledge transfer between an organization and a community that it serves. Citations had to fulfill the following criteria to be included in this study:

- Either description of interaction between an organization and a community, or description of knowledge transfer from a community to an organization as a means of contributing to organizational learning, change or innovation;

- Reference to 'learning,' either through description of organizational learning structures, processes or outcomes or description of elements of a learning organization or learning health system;

- Description of the relationship between the organization and community as one in which the community should benefit from organizational outputs;

- Description of learning occurring at the level of the organization.

Provided that they met these criteria, citations were included based on an inclusive understanding of 'community' (e.g., client, customer, patient, consumer, public). Citations were excluded if they: focused on interorganizational learning or professional communities of practice; described learning at a level other than the organization; were written in a language other than English; or offered insufficient evidence, typically because they were book reviews or short commentaries. All criteria were piloted against 10 purposively selected journal articles and refined before any screening.

\section{Study selection}

Before screening began, two reviewers (initials removed for double-blind peer review) piloted the eligibility criteria and Rayyan, a web-based screening tool [48], using a preselected list of 27 citations. They then conducted a first phase of screening. Over four rounds, the two reviewers screened the titles and abstracts of $524(27 \%)$ citations with the objective to reach consistent inter-rater agreement above $80 \%$. Agreement in each successive round was $74 \%, 81 \%, 83 \%$ and $92 \%$, respectively, with conflicts resolved through discussion. The lead author screened the remaining 1,423 (73\%) titles and abstracts independently. Where there was not enough or unclear information to exclude a citation, the citation was included for full-text review. In total, 98 citations were screened in. Their full texts were reviewed against the eligibility criteria by the same two reviewers who performed title-abstract screening. Disagreements were resolved by consensus. One additional citation was included at this stage after reviewing the reference lists of all full-text documents. Our process is illustrated in Fig. 1 below.

\section{Data charting and collation}


Using a pre-set chart in Excel that had been pilot tested on a sample of five included texts, the lead author extracted data with regard to numerous variables including article characteristics (e.g., discipline, study design, objective, findings); theoretical frameworks and definitions; dimensions of learning (e.g., processes, structures, motives, outcomes); and community variables (e.g., conceptualization of community and community roles). Data related to power relations and ethical tensions were also extracted on the basis that organizations and communities could face power differentials and ethical ambiguities in their learning relationship $[11,49]$. Results were synthesized using frequencies and thematic analysis [50]. Meta-analysis was not performed.

\section{Search update}

We updated our results in August 2020. The lead author performed the same search detailed above, limiting results to items published in 2019 or 2020. The lead author performed study selection and data charting independently, applying the same eligibility criteria as above. Overall, we found that literature published since the initial search in March 2019 did not produce any significant new insights, which reflects the singularity of this work.

\section{Results}

\section{Literature search}

A total of 1,947 titles and abstracts and 99 full-text documents was assessed for eligibility during the initial search in March 2019. Of these, 38 full-text documents fulfilled our eligibility criteria. Two documents were excluded because they could not be retrieved through (library name removed for doubleblind review), and 56 were excluded for not describing either learning from or with community, organizational-level learning, or both. Two short commentaries and one short conference paper were excluded as they did not make substantive empirical or theoretical contributions. During the study update of August 2020, an additional four full-text documents met our eligibility criteria [51-54]. Therefore, we included a total of 42 full-text documents in this analysis.

\section{Characteristics of included documents}

The final 42 documents reflected the research disciplines of health services (encompassing learning health systems), business, natural resource management, organization and management sciences, education and social services. As in Table 2, the majority of documents $(67 \%)$ were published within the last ten years and originated predominantly in the United States (36\%), Canada (14\%) and the United Kingdom (10\%), or from multi-country settings (10\%). Although most authors (64\%) did not report a funding source, nearly a quarter were funded by public sources (24\%). Most documents were published within the business (36\%) and health services (31\%) disciplines, though it is interesting to note that among the 26 empirical studies, 13 (50\%) came from business studies, followed by only three (12\%) from health services research and three $(12 \%)$ from natural resource management. Most documents focused on organizational learning (57\%), followed by learning health systems $(19 \%)$, learning organizations 
$(17 \%)$ and social learning (7\%). The most common type of document overall was an empirical study (62\%), of which half (50\%) were qualitative studies.

Definitions and theoretical grounding 
Table 2

Document characteristics ( $n=42$ )

\begin{tabular}{|c|c|c|c|}
\hline \multirow[t]{5}{*}{ Year of publication } & 1995-1999 & 3 & $(7.1 \%)$ \\
\hline & $2000-2004$ & 7 & $(16.7 \%)$ \\
\hline & $2005-2009$ & 4 & $(9.5 \%)$ \\
\hline & $2010-2014$ & 11 & $(26.2 \%)$ \\
\hline & $2015-2018$ & 17 & $(40.5 \%)$ \\
\hline \multirow[t]{7}{*}{ Geographic region } & Africa & 1 & $(2.4 \%)$ \\
\hline & Asia & 6 & $(14.3 \%)$ \\
\hline & Australia and New Zealand & 1 & $(2.4 \%)$ \\
\hline & Europe & 6 & $(14.3 \%)$ \\
\hline & North America & 21 & $(50.0 \%)$ \\
\hline & Multi-country & 4 & $(9.5 \%)$ \\
\hline & Not specified & 3 & $(7.1 \%)$ \\
\hline \multirow[t]{4}{*}{ Funding source } & Private-sponsored & 3 & $(7.1 \%)$ \\
\hline & Public-sponsored & 10 & $(23.8 \%)$ \\
\hline & Non-sponsored & 2 & $(4.8 \%)$ \\
\hline & Not reported & 27 & $(64.3 \%)$ \\
\hline \multirow[t]{6}{*}{ Research discipline } & Business & 15 & $(35.7 \%)$ \\
\hline & Health services & 13 & $(31.0 \%)$ \\
\hline & Natural resource management & 5 & $(11.9 \%)$ \\
\hline & Organizations and management science & 5 & $(11.9 \%)$ \\
\hline & Education & 2 & $(4.8 \%)$ \\
\hline & Social services & 2 & $(4.8 \%)$ \\
\hline \multirow[t]{4}{*}{ Focus } & Organizational learning & 24 & $(57.1 \%)$ \\
\hline & Social learning & 3 & $(7.1 \%)$ \\
\hline & Learning organization & 7 & $(16.7 \%)$ \\
\hline & Learning health system & 8 & $(19.0 \%)$ \\
\hline \multirow[t]{2}{*}{ Document type } & Empirical study & 26 & $(61.9 \%)$ \\
\hline & Theoretical paper & 7 & $(16.7 \%)$ \\
\hline
\end{tabular}




\begin{tabular}{|llll|}
\hline Year of publication & 1995-1999 & $\mathbf{3}$ & $\mathbf{( 7 . 1 \% )}$ \\
\hline & Descriptive study & 2 & $(4.8 \%)$ \\
\hline Empirical study & Other* & 7 & $(16.7 \%)$ \\
\hline approach & Qualitative, case study design & 8 & $(30.8 \%)$ \\
\hline & Qualitative, participatory action research & 1 & $(3.8 \%)$ \\
\hline & Other qualitative design & 4 & $(15.4 \%)$ \\
& Quantitative, survey/questionnaire & 11 & $(42.3 \%)$ \\
& Quantitative, experimental design & 1 & $(3.8 \%)$ \\
\hline * Commentary, conference proceedings, knowledge synthesis report or editorial \\
\hline
\end{tabular}

Only 26 documents provided definitions of either organizational learning, social learning, learning organization or learning health system. We found considerable variation in the conceptual and theoretical moorings of the definitions that each of these texts provided.

Whereas definitions of organizational learning and social learning clearly focused on learning processes, definitions of learning organizations and learning health systems focused on learning outcomes. Only four texts explicitly mentioned learning from or co-producing knowledge with community as part of their definitions [22, 55-57]; among them, two focused on learning health systems [22, 57]. Social learning articles de-emphasized organizational structures or boundaries and instead highlighted transformative group processes with all relevant knowledge holders $[55,58]$. Learning health system documents were the only ones not to consider transformation of underlying group norms, assumptions or behaviour as part of the definitions they used, though some did acknowledge the importance of human interactions for learning and knowledge dissemination $[57,59,60]$.

Definitions for learning organization and learning health system were the only ones to consider the generation of evidence through practice. Definitions for learning health system were the only ones that prioritized the generation of evidence specifically through research. Informatics and digital data infrastructure were part of the definitions offered by three documents only, all of which pertained to learning health systems $[22,57,61]$.

Interestingly, not one healthcare text drew from theory in defining any of the four terms. The learning health system texts were strikingly detached from theory, instead citing practice-based definitions and frameworks encompassed in the National Academy of Medicine's numerous reports [e.g., 22, 62, 63]. Learning organization documents were rooted in preestablished frameworks-notably Senge's [35] five disciplines of system thinking, personal mastery, mental models, shared vision and team learning- 
without attempting to build upon them. Only two learning organization texts explored associations between other concepts to innovate new models for understanding change and learning by organizations $[64,65]$. Garvin [66], Marquardt [67] and Burgoyne et al. [36]-whose works, like those of Senge, were set in a non-healthcare business environment-were also consistently cited in the learning organization literature.

Documents that focused on organizational learning consistently incorporated theoretical concepts such as single- and double-loop learning [28, 29], exploration and exploitation [16], absorptive capacity [68] and tacit and explicit knowledge $[69,70]$. They also frequently cited prominent theorists such as Cyert and March [71], Huber [30] and Levitt and March [72]. The organizational learning texts engaged deeply with these concepts and proposed associations with other constructs such as organizational effectiveness [73], empowerment [74] and trust [75]. The social learning articles were rooted in situated learning [17] and transformative learning [33] and supported a framework of co-management by the organization and all its stakeholders.

\section{Organizational context}

Whereas 16 documents described public service or other non-profit settings, 18 described organizational learning in the private sector. Although no patterns by document type were found, we noted that six documents held very broad conceptualizations of the external environment rather than bounding the environment within a given sector or offering more nuanced descriptions of what the external environment comprised [55, 56, 58, 76-78]. For example, Hafkesbrink and Schroll [76] simply described the external environment as the surrounding communities into which an organization can be integrated. For their part, Nonaka et al. [56] suggested the only significant boundary is that between the Self and the Other as individual knowledge becomes collective and accumulates through continued interaction between the organization, its members, and members in the external environment.

\section{Conceptualizing community}

The texts conceptualized community in different ways. Thirty-two $(76 \%)$ conceptualized community as the collective or individual users of a service or product. By contrast, Bess et al. [73] described community as the local geographic area or micro-environment, stressing that the extent to which communities are viewed as knowledge sources depends on the definition of organizational boundaries and membership, determining whether community members are considered members of the organization or partners. They cited one example of an inclusive definition of organizational membership, comprising clients and volunteers, that augmented organizational learning capacity.

All five natural resource management texts held broad conceptualizations of community, defining it as the public or other interested stakeholders $[55,58,74,77,79]$. They emphasized social processes of dialogue and transformative learning at the organizational and societal levels, where the organization must resist imposing its own structures in its external environment, or else marginalize the community's ability to solve problems. Only one of these articles emphasized 'learning from' community preferences rather than 'learning with' the community in relationship and dialogue [58]. 


\section{Learning from, and learning with, community}

Ten $(24 \%)$ texts suggested that organizational learning could be done with community $[22,56,57,60,74$, $77,80-83]$. Nine (21\%) texts suggested that organizations could learn both from and with the communities they served $[52,55,59,64,78,79,84-86]$. Learning by the community was not explored. As for the role of community in organizational learning, in most texts this was either not mentioned $(n=13$, $31 \%$ ) or described as a passive role of allowing data collection, consultation or information use by the organization ( $n=16,38 \%)$. A minority of texts described community as having a more active role in addressing its own problems [74, 78], thus driving innovation [87] or collaborative design and management $[22,58,76,88]$, yet they nonetheless offered limited detail to understand this role.

More than half the documents $(n=22,52 \%)$ described 'learning from' community. Business texts tended to talk about customer knowledge management or collecting data about customers to learn their needs, preferences and spending patterns. Healthcare texts also tended to focus on collecting patient data. Indeed, 13 articles oriented toward knowledge management indicated the organization had a role in collecting and managing information about or from the community $[51-54,56,61,75,83,88-92]$. Four texts alternatively described the organization's role in terms of exploration and exploitation [87, 93-95]. Other roles for the organization that were described included ensuring its members engaged in boundary spanning to liaise with customers [65], ensuring communities are recognized as valuable sources of knowledge and agency $[74,77,78]$ and providing a structure for learning and community engagement $[55,73]$.

Three texts suggested that community engagement could be measured on a continuum [59,64, 74]. They each recognized a need to engage with community through dialogue and co-creation of knowledge and conceived an association between the level of engagement and the quality of organizational learning. Their work also implied that learning with community required more effort from the organization because it enacted participatory methods [59], but that this was preferable to simply gathering information about the community or gathering feedback. In a like manner, though they did not present a continuum of engagement, Bess et al. [73] described a partnership mindset as a beneficial alternative to the conventional expert-client relationship.

\section{Knowledge transfer}

Thirty-four (81\%) texts went beyond ambiguous references to community participation to provide insight into the nature of knowledge transfer between the community and organization. In 17 of these texts, community knowledge and evidence were described as flowing to the organization through direct interaction and relationships, for example through volunteering or board membership $[73,81]$ or participation on advisory councils $[57,60]$. The authors of six documents spoke about knowledge transfer as a self-reinforcing cycle of learning between the community and organization wherein open, crossboundary dialogue facilitates the flow of ideas $[56,65,78,83,94,96]$. Yanow [78] described organizational members as bicultural translators who translate knowledge along a double periphery: vertically through the organization and horizontally across organizational boundaries, where they interact 
with non-members. Three articles suggested that there must be an open space of discourse for community evidence to mix with organizational knowledge and help to transform organizational frames of reference [77-79].

Four healthcare texts $[61,91,92,97]$ and three business texts $[54,89,90]$ emphasized community knowledge and evidence flowing in the form of administrative or research data about the service or product user. Two business documents described data flowing through a third-party, whether a parent company [93] or another organization to which customer relationship management is outsourced [75].

Five texts incorporated the concepts of tacit and explicit knowledge $[53,56,76,83,94]$. Cegarra-Navarro and Dewhurst [94] suggested that knowledge begins as individual, tacit knowledge and then becomes collective and explicit as it is consolidated, stored in organizational memory, and exploited by organization members. Nonaka et al. [56] proposed a theoretical model for understanding internalization (explicit-to-tacit knowledge conversion) in addition to externalization (tacit-to-explicit), socialization (tacitto-tacit) and combination (explicit-to-explicit) processes as knowledge is gathered, shared and converted through interaction. Jaziri [53] draws on this model to argue that the lived experience of a customer is valuable tacit knowledge for the organization that should be externalized through dialogue. Hafkesbrink and Schroll [76] described how knowledge sharing becomes more difficult between different groups who may not already share common tacit knowledge.

\section{Motives and outcomes}

The stated motives behind organizational learning from or with community were wide-ranging. Nineteen $(45 \%)$ documents cited a desire to improve the implementation of a service or policy. Fifteen $(36 \%)$ documents, nearly all from business research, cited a desire to enhance competitive advantage and market performance. Three natural resource management articles framed their learning motive as the need to solve societal problems $[55,58,79]$ and one management article cited a need to refine internal routines or procedures and expand stores of knowledge [80]. Yanow [78] felt that learning evolves naturally through experience as a natural by-product of members doing their jobs in interaction with members of the external environment.

What organizations were said to learn from or with community also varied. For example, organizations gained knowledge about how to improve [e.g., 75, 76, 96], patient care and experience [e.g., 22, 91, 92] and alternative perspectives of what counts as evidence [98]. Campbell [93] conceded that many firms know little about how to use the information they hold about their customers.

The texts lacked detailed understanding of the processes that link learning motives to outcomes. For example, while clearly describing their motivation for learning as an interest in enhancing organizational capacity to innovate, Bess et al. [73] failed to describe generative, second-order learning processes or outcomes and instead focused on the integration of external information for first-order decision-making. Indeed, business and healthcare articles typically focused on first-order change, such as improving services to attract customers or clients. One book chapter suggested that to take the organization to 
double-loop learning and second-order change, the organization needed to truly value the ideas, perspectives and information held by customers [89]. Only seven texts described second-order change as an outcome, either framed as second-order change [95], double-loop learning [64], innovation [89], community empowerment [74], social change [79] or transformed values and assumptions [58, 85]. Four of these seven texts described organizational learning with community rather than from the community $[64,74,79,85]$.

\section{Structures and processes}

All texts except two $[94,99]$ contemplated structures to support organizational learning from or with community. Five healthcare texts $[22,61,91,92,97]$ and four from business $[54,75,89,93]$ emphasized that learning about or from patients or customers occurred by harnessing data for knowledge translation. Reid and Hickman [64] went further, arguing that organizational learning depends on participatory structures and relationships with community. Kass and Faden [91] implied that in healthcare, the structure for organizational learning is the learning health system, but did not explore this structure beyond its obligations and guiding principles. Some authors saw information technology as a structure unto itself $[61,92]$ whereas others felt that technology played more of a supporting role $[87,89,97]$.

Across all documents, the distinction between structures and processes was unclear. In some texts, the organization-community relationship was seen as both structure and process. For example, several texts indicated that customer knowledge management $[52,54,83,88]$, customer relationship management [75, $93,96]$ or customer experiential knowledge management [53] formed the architecture for learning from or with community. Authors generally referred to processes in limited detail, and focused instead on characteristics like patient advisories, boards and other frameworks for external engagement with a seeming assumption that beneficial learning processes would follow. Some made reference to boundary spanning [80, 84, 95]; absorptive capacity [75, 84]; tacit and explicit knowledge conversion [56, 65, 76, 78, 83, 87]; and rational, reflective discourse $[55,77,79,95,100]$. Two texts saw a role for government, either to support communities in their own learning to solve local problems [74] or to mandate collaboration between organizations and the communities they serve [58].

\section{Strategies}

The most frequently cited strategy to support organizational learning from or with community, clearly mentioned in 19 (45\%) texts, was the maintenance of relationships and social interaction with the external environment [e.g., 56, 75, 80, 81, 86, 96]. Ten (26\%) texts recommended creating a culture or vision that openly values external knowledge [e.g., $22,85,97,100]$. Nine texts recommended designing internal structures to support access, interpretation and sharing of information [e.g., 53, 55, 60, 89, 97]. Nonaka et al. [56] provided the most insight as to what such an internal structure may look like, describing a common space or context shared between individuals and groups where knowledge is created, shared and utilized; this shared context, they suggested, can be a physical space or a virtual one, whose boundaries emerge and adapt as needed. Six articles suggested that the organization must proactively work to build its learning capabilities and competencies $[54,65,76,84,96,97]$. Five texts 
advocated for structures or policy to integrate community voice into decision making $[57,59,60,64,73]$. These strategies are depicted in Fig. 2.

Other recommended strategies included establishing means to encourage debate, critical reflection and inquiry $[56,75,79,99]$; ensuring appropriate demographic representation in learning $[60,73,82]$;

supporting boundary spanners as they search for and funnel community knowledge into the organization [78, 95]; and balancing exploitation and exploration functions [52, 76, 94].

\section{Power relations}

Trust and transparency were prominent themes among the $10(26 \%)$ texts that explored power relations between the organization and community $[55,74,77-81,85,86,98]$. Russell [74] highlighted a perceived lack of trust in government among community-based organizations and therefore emphasized the importance of equal partnership. This sentiment was repeated by others who felt that balanced power relations were necessary for organizational learning outcomes to benefit the community. For Ochocka et al. [85], equal partnership needed to replace a paternalistic 'expert' role for the organization vis-à-vis community. Ryan [86] asserted that whereas trust should be earned, organizations typically enter into community relationships holding significant unearned control and privilege.

Other texts dealt tangentially with power relations through acknowledgement of the need to 'empower' patients [22]; preference for strengths-based and respectful terms such as 'service partner' [81]; and recognition that redefined relationships, structures and hierarchies are needed for both organizations and communities to benefit from collaboration. In their article, Curado et al. [52] labeled customers as 'knowledge partners' yet did not position them as equal partners, nor did they acknowledge the power relations that may come into play.

\section{Distinct knowledge systems}

Four texts paid considerable attention to the position of community knowledge systems relative to organizational, professional or scientific knowledge [55, 77-79]. Yanow [78] observed that power and privilege are associated with knowledge, describing how local knowledges are habitually devalued compared with university-based scientific knowledges. Yanow maintained that organizations either support or hinder the translation and sharing of community knowledges, depending on whether they value or devalue community knowledges relative to other knowledge systems. Kelsey [77] claimed that a 'science-first' model-founded on a historical predisposition of western science to regard local knowledges as anecdotal, unsubstantiated and of little value-unduly elevates the relative importance of scientific knowledge, thus marginalizing local knowledge and restricting the ability of communities to participate in learning processes. This corresponds with the suggestion by Nonaka et al. [56] that although both explicit and tacit knowledges are essential to knowledge creation, western epistemology has traditionally favoured an explicit conceptualization of knowledge.

Just as Diduck et al. [79] argued there are "privileged definitions of rightness," other texts acknowledged that community knowledge is not always recognized as valued or reliable [76, 89]. Egunyu et al. [58] 
suggested that community participation narrows over time to those with seemingly acceptable knowledge and skills. Transformative learning, sustained by multiple knowledges and perspectives, was seen as required to change this asymmetry $[55,79]$.

\section{Ethics}

Four $(11 \%)$ healthcare texts raised ethical concerns that emerged from the tension between respecting patient privacy and striving to ensure research results are rapidly disseminated for learning $[57,61,85,91$, 97]. Identifying ethics and oversight as a crucial component of a learning health system, Psek et al. [57] questioned the utility of distinctly separate frameworks for patient care and research. Other ethical debates considered which organizational learning activities require ethical approval [97], how patients should be engaged in research $[91,97]$, and how to translate research results so they benefit patients [61, 91].

\section{Discussion}

Using scoping review methodology, our study aimed to determine what is known in extant literatures about organizational learning from or with community, particularly on the part of learning health systems. However, it is just as interesting to note what is not known, namely that across disciplines, the potential importance of communities to organizational learning and learning health systems is understudied. This apparent inattention runs counter to longstanding recognition in the organization sciences that internal and external processes and knowledge sources profoundly influence organizational learning [16, 68, 101, 102]. If we are to establish a strong understanding of how learning takes place and knowledge is created within a learning health system, it seems sensible to be attentive to all processes for learning and all sources of knowledge.

In the meantime, our results point to a number of other implications and gaps with regard to understanding and implementing learning health systems as social entities and spaces. In this discussion, we highlight areas that should be considered.

\section{Learning motives}

This review makes clear that organizations do not all learn for the same reasons. Our findings highlight distinctions in ways of being or knowing among the multiple research disciplines included in this studya source of variation in our analysis. For example, whereas business texts consistently described the organization's motive to learn as a desire to enhance its own competitive advantage and market performance, three of the five natural resource management articles described a motivation to solve problems on a societal scale. These results align with a schema proposed by Easterby-Smith [27] wherein the business sector can be seen to hold an ontology of 'competitiveness,' and natural resource management seemingly holds an ontology of 'social structures.' Such one-sidedness in our results, generally favouring organizational performance over impact in the external environment, should give health services researchers pause to reflect on approaches to conceptualizing, building and implementing 
a learning health system. Ricciardi et al. [103] make a compelling argument for a systems dynamic approach that considers not just organizational performance, but also the place of the organization in the broader system and what the organization can learn in order to contribute to the common good. If the goal of a learning health system is to improve the health of a population-not simply perform within the confines of organizational boundaries and compete with other healthcare organizations-it seems logical to consider learning at multiple system levels, including from or with community.

\section{Reimagining organization-community relationship}

A complex adaptive systems lens points to relationships as not only the building blocks of an organization, but also a core ingredient for learning. Although direct relationships and knowledgeintensive interactions between people are needed for organizations to overcome any barriers to learning from locally-embedded knowledge [104], it is not immediately apparent what the organization-community learning relationship might look like. We noted throughout this review that 'relationship' means many things in the literature, from connection and interactions between different parties, to a one-way flow of data about one party to the other. With diverse meanings and models of relationship in play, it is unclear which kinds of relationships best support organizational learning. Furthermore, there is little guidance regarding how to establish learning relationships with arguably the most important actor(s) in the organization's external environment.

We discovered a tendency to concentrate on collecting information 'about' community [e.g., 89, 90, 92, 96] as part of 'learning from' community. This is in contrast to 'learning with' community, a distinction that is crucial for its indication of the balance of power and privilege in the learning relationship [105]. 'Learning about' community risks reducing the community's position to that of merely 'being known' rather than enhancing community capacity to 'know.' It follows that 'learning with' community is a defining characteristic of the learning relationship in which the organization and community are both empowered to exchange their knowledges and ways of being and knowing, on equal footing in terms of value. This line of thinking offers considerable conceptual clarity for building and nurturing organizational learning relationships with communities yet is by no means new. In healthcare, literature on public and serviceuser involvement already distinguishes between consumerist ('learning about' or 'learning from') and democratic ('learning with') models [106-108]. What remains is to apply these concepts to theoretical and empirical analyses of organizational learning and, more specifically, learning health systems.

'Learning with' community would require a healthcare organization to be comfortable with the possibility of double-loop learning and any change deemed necessary by that learning. The organization may give an illusion of legitimacy and partnership by labelling the community as an equal learning partner $[64,80]$. However, if the partnership is founded in rhetoric more than reality, the extent to which the organization can learn from communities is unclear. Listening, largely neglected in research as a part of discourse [109], may be a precondition for learning. In the least, the extent to which an organization can listen and learn from communities is influenced by the characteristics of its relationships, including the balance of power. 


\section{Knowledge and power}

A vital resource, knowledge accords power over oneself and also over others [110]. Moreover, there is likely to be an in-built power imbalance between the organization and community, which influences learning [111]. As already discussed, there are conspicuous differences between learning about a community as a research subject and participating in joint learning with that community to co-generate new knowledge, notably the distribution or share of power in the relationship. Political decision making and unequal relationships impose inherent barriers to the co-production of knowledge, something that has been found in numerous studies of healthcare organizations where ostensibly participatory, citizenled mechanisms were manipulated to co-opt power and serve preconceived organizational goals, eroding community trust $[106,112,113]$.

According to transformative learning theory, oppressive structures are overcome through intensive discourse that leads to the formation of new 'habits of mind' more in line with goals of social justice [114]. Learning with community therefore presents a potential opportunity to transform underlying assumptions and values of the organization and shed cultures or standards that dominate and prevent the full participation of others in the organization. The complexity science concept of adaptive space assists in understanding how the learning relationship might unfold insomuch that the organization is compelled to create an atmosphere where members and non-members feel safe sharing their knowledge [15]. Nonaka et al. [56] proposed a similar concept, ba, described as the shared context from which all knowledge creation emerges. Their description of experiential, conceptual, systemic and routine assets, as well as four types of ba defined according to various manners of interaction, provide insight as to what actually goes on in adaptive space, but the structures and processes of learning relationships comprise an area for future investigation.

\section{Ways of learning}

Learning health systems literature may be dominated by discussions of electronic health records as a primary source of evidence [63], but we must see such technology for what it is: a useful tool for widespread transmission of explicit knowledge that helps to create a virtual collaborative environment, not a complete picture unto itself. Nor can we lose sight of the influence of culture on knowledge sharing, with some cultural groups favouring document-based sharing of codified explicit knowledge and others preferring tacit knowledge shared via human networks [115]. An evidence framework that honours the explicit and tacit knowledges in the organization and community would do much to ensure organizations maintain a holistic awareness of their roles, risks and opportunities in the local context.

The learning health system-or any learning organization, for that matter-may be best supported by a combined approach of emergent organizational learning and deliberate research, with structures in place to support both processes. Throughout this study, we saw an ostensible tension between learning and research. Certainly, both learning and research involve the accumulation of knowledge, but they differ with regard to intentionality, formality and apparatus. Healthcare systems already field criticism for performance management frameworks that overemphasize explicit standards and measures, sometimes 
leading organizations to forsake service for targets [116, 117]. It is not unreasonable to suppose there may exist a bias toward explicit and research-derived knowledge in healthcare circles.

The learning health systems texts included in this review support this idea. They were singularly focused on generating evidence through research, revealing a divide between this subset of the literature and others related to organizational learning or learning organizations. Their research focus raises a number of ethical questions, including those regarding whose purposes are served (e.g., are patients included in defining research questions?); structures of learning (e.g., will research be integrated with organizational practice, or siloed?); and sources of learning (e.g., do organizations learn from patient registries or from patient encounters?). Arguably just as problematic, one recent study suggests that only a minority of community members feel a responsibility to participate in healthcare research [118]. We speculate that the overwhelming propensity for research and evidence-based medicine could inadvertently, and perversely, steer health system planning away from models of relationship-centered care and toward a firm predilection for explicit research-based knowledge over tacit knowledge from other sources.

\section{Looking inward to learn with others}

As the learning health system searches the external environment, it must also look inward to ensure the integrity of its internal learning structures and processes. Just as there are external processes and capabilities for learning, such as exploration and recognizing the value of external knowledge, there are internal processes and capabilities as well, including selection, reflection and replication [101]. Attention to internal structures and processes may, in fact, partly comprise the threshold between 'learning from' and 'learning with' community. Our results suggest that a single-minded mentality of knowledge acquisition, via data extraction about or from the community, may preclude relationship with that community. Such a mentality may also be ingrained in the organization that creates structural mechanisms (e.g., a patient advisory body) as assumed proof of legitimacy, without concern for actual processes of meaningful community engagement.

The organization that openly welcomes communities into the inner workings of its adaptive space simultaneously creates opportunities for communities to contribute their knowledges and perspectives in the interpretation, dissemination and integration of new learnings. The organization must therefore build internal structures for learning relationships to occur and be able to diffuse their knowledge.

The site of greatest activity in this relationship is where different ideas and knowledges are allowed to mix, conflict and generate adaptive tension. Whether called adaptive space or $b a$, this emergent space is where members of the organization and community exchange explicit knowledges, through dialogue and data sharing, concurrently with tacit knowledges, through relationship and social interaction. These exchanges equate to the knowledge conversion processes of combination and socialization as described by Nonaka et al. [56]. As members of the organization and community offer and develop their ideas free from judgment, they forge shared mental models and context for continuous knowledge accumulation and learning. Through ongoing externalization and internalization, explicit and tacit knowledges are subsequently converted from one type to another within the organization and community [56]. In this way, 
communities become partners in contextualizing data and determining which evidence best applies in their contexts.

The challenge in practice is to sustain the autonomy and influx of community perspective. It may be that the longer community representatives are integrated within organizational structures, the more their culture and bias begin to align with that of the organization rather than the community-especially if they are receiving some kind of remuneration for their contributions. To respect and maintain the integrity of community knowledges, the organization would need to partner with the community to set up initial structures, processes and boundaries for collaborative learning as well as be open to changes the community may suggest over time.

Developing an enhanced understanding of routines in the context of organizational learning from or with community will be central to addressing this challenge and honing internal learning structures and processes. As the foundation of an organization's processes and capabilities [119], routines also store organizational knowledge and memory. Over time, inferences are embedded into routines that guide organizational behaviour regardless of the individual actor who executes them [72]. Managers must mindfully employ routines to enable the conditions for learning among their staff and at the level of the organization as a whole. These conditions include judgement-free spaces for the intermixing of different ideas and a vision that values learning in general and learning with community specifically. Using inclusive methods that encourage critical reflection, managers must design interactions within and outside the organization that facilitate sharing of explicit and tacit knowledge in addition to selforganization as new things are learned. Of course, these are not straightforward tasks. Contextualized investigation into routines would provide invaluable, practical guidance for the learning health system that learns from communities.

\section{Learning as transformation}

One popular perspective on the outcome of organizational learning is that learning results in a change in the range of the organization's potential behaviours [30]. This definition is simple and efficient but does not correspond with the intent inherent to learning organizations and social learning to move beyond potential change and take action. Although largely modelled on individual processes of reflection, the literatures seem to have embraced the concept of transformative learning and accepted its application to group processes as well. Organizations seeking to engage in transformative learning attempt to transform problematic habits of mind and take action based on a new, more justified perspective [114, 120].

Some authors warn that transformation may not always be preferable or lead to the best outcomes for an organization [26]. There are nonetheless real reasons to contemplate second-order change and transformation of the structures, processes, values and assumptions that underlie healthcare organizations, such as the need to improve the accessibility and quality of care for systemically marginalized groups. Moreover, experimentation and transformation may be needed for organizations to instill the culture of learning and relationships needed to become learning health systems. There is an

Page 21/33 
opportunity for further study and reflection to gauge the value of double-loop learning or other secondorder change and transformation, and how this might be supported as a collaborative process.

\section{Theoretical guidance}

Our results confirm that the learning health systems literature, though it reflects a keen interest in learning organizations within the healthcare sector, is essentially atheoretical. Additional investigation to explore and verify associations between social relationships, structures, processes, types of knowledge and outcomes would contribute specificity in terms of the different definitions and meanings attributed to learning health systems and learning organizations more broadly, and possibly clarify which types of learning (e.g., learning from or with community; adaptive or transformative learning), driven by which motives, lead to better outcomes. Theoretical and empirical multidisciplinary exploration could also assist in coming to a consensus on the defining characteristics of a learning health system.

\section{Strengths and limitations}

We endeavoured to make a singular contribution to learning health systems and other organizational learning literatures by drawing from diverse research disciplines in order to map what is known about learning from or with community. Consistent with scoping review methodology [42, 43], this review did not include critical appraisal of the quality of the research reported in included texts. In this light, we attempted to avoid making inferences in our results beyond what was clearly stated by the authors. We also attempted to mitigate any researcher bias with a second reviewer and regular consultation among co-authors during data abstraction and analysis. Furthermore, given the current dearth of literature, we did not differentiate between community as a collective and community as represented by an individual. This distinction could be made in future research. Finally, this work did not include consultation with community partners, which would be invaluable in future study.

\section{Conclusions}

There is substantial work still left to do if we are to progress the concept of a learning health system from the abstract into practice. In this study, we looked across research disciplines for guidance, contributing to a more comprehensive evidence base for building and operating a learning health system. Broadly speaking, learning health systems literature would benefit from additional research within a sociological paradigm so as to better understand the social relations and structures that play a role in the dynamics of organizational learning. The integration of sociological perspectives, combined with rigorous examination of organizational constructs such as routines, may shed light on the sociocultural factors and practices that influence and enable learning.

Taking a novel approach, this study shines a spotlight on actors most often overlooked: the communities that an organization serves. Despite longstanding recognition that learning from internal, familiar knowledge through processes of exploitation goes hand in hand with exploration in the organization's external environment $[16,68,101,102]$, organizational learning from and with the communities it serves is sorely understudied. Our findings revealed inconsistently defined concepts and associations, tenuously 
linked with their theoretical and empirical origins. In light of multifarious conceptualizations of the structures, processes, motives and outcomes of learning, and even of community, there is a need for theory-building as well as empirical study focused on establishing key concepts and associations to understand the nature of learning with community and how to make it happen. Research might also explore not only how clinicians, administrators and other health system professionals in a given geographic area perceive community knowledge, but also, importantly, how communities they serve perceive health system knowledge. Reciprocity and mutual respect would be necessary for any truly collaborative learning effort.

We found little evidence that organizational learning is taking place in equal relationship and partnership with communities. Even so, the consequence of relationship with communities in the external environment nonetheless came out strongly in our results, along with the recognition that social norms and power relations can make or break a relationship. What a learning health system learns, how it learns, and to what effect are intimately tied with who contributes to learning. Diversity, not merely in membership but also in discourse, cultivates ideas, drives adaptation when needed and leads to more rationally-justified outcomes $[15,121]$. However, the value of learning with community extends beyond simply diversifying the knowledge base of organizations. As members of the social context, communities extend our conceptualization of what 'counts' as evidence. Striving toward evidence-based medicine and decision making, our reliance on purely explicit knowledge-stripped from context in the name of objectivity-provides only a partial picture. Communities represent a relevant source of knowledge that is discrete from organizational, scientific or other forms of knowledge; surely, their knowledge counts as evidence, too.

Looking inward is fundamental for the organization, not only as part of a self-reflexive practice, but also to establish internal structures and processes for interpretation, dissemination and integration of new knowledge. These processes are essential to realizing the value of new knowledge to the organization's operations. It may take some effort to find the ideal balance between embedding community too little or too much, but we believe that healthcare organizations are likely to find their community relationships to be rich sources of information, tacit or otherwise, about that context. In fact, if future study proves these things to be true, the learning health system may be, by definition, one whose culture, structures and processes afford a meaningful shared context for social interaction and knowledge co-creation with the communities it serves, with borders extending beyond the traditionally defined organization. Such would be a context wherein the organization's relationships are defined by true partnership in place of rhetoric.

\section{List Of Abbreviations}

Not applicable.

\section{Declarations}

Ethics approval and consent to participate 


\section{Consent for publication}

Not applicable.

\section{Availability of data and materials}

Data generated or analysed during this study are included in this published article and its additional files.

\section{Competing interests}

The authors declare that they have no competing interests.

\section{Funding}

CM received support during this work as a Canadian Institutes of Health Research 2019 Vanier Scholar. The Canadian Institutes of Health Research had no involvement in this study.

\section{Authors' contributions}

CM conceptualized the study and led data collection, analysis and interpretation, and writing of the manuscript. DW was the second reviewer in the scoping review. WB supervised the study and contributed to writing the manuscript. All authors read and approved the final manuscript.

\section{Acknowledgements}

We thank (removed for double-blind review) for her expert assistance in developing the search strategy.

\section{References}

1. Institute of Medicine: The Learning Healthcare System: Workshop Summary. Washington, DC: The National Academies Press; 2007.

2. Budrionis A, Bellika JG: The learning healthcare system: where are we now? A systematic review. Journal of Biomedical Informatics 2016, 64:87-92.

3. Friedman C, Rubin J, Brown J, Buntin M, Corn M, Etheredge L, Gunter C, Musen M, Platt R, Stead W: Toward a science of learning systems: a research agenda for the high-functioning Learning Health System. Journal of the American Medical Informatics Association 2014, 22(1):43-50. 
4. Greene SM, Reid RJ, Larson EB: Implementing the learning health system: from concept to action. Annals of Internal Medicine 2012, 157(3):207-210.

5. Collyer F: Envisaging the healthcare sector as a field: moving from Talcott Parsons to Pierre Bourdieu. Social Theory \& Health 2018, 16(2):111-126.

6. Rashman L, Withers E, Hartley J: Organizational learning and knowledge in public service organizations: A systematic review of the literature. International Journal of Management Reviews 2009, 11(4):463-494.

7. Lane PJ, Lubatkin M: Relative absorptive capacity and interorganizational learning. Strategic Management Journal 1998, 19(5):461-477.

8. Ingram P: Interorganizational learning. In: The Blackwell Companion to Organizations. edn. Edited by Baum J. Hoboken, NJ: Wiley; 2017: 642-663.

9. Dixon N: Organizational learning and the learning organization: Developments in theory and practice. In: Organizational Learning and the Learning Organization: Developments in theory and practice. edn. Edited by Easterby-Smith M, Araujo L, Burgoyne J. London, UK: Sage; 1999: 115-129.

10. Usman M, Ahmad MI, Burgoyne J: Individual and organizational learning from inter-firm knowledge sharing: A framework integrating inter-firm and intra-firm knowledge sharing and learning. Canadian Journal of Administrative Sciences/Revue Canadienne des Sciences de I'Administration 2019, 36(4):484-497.

11. Armitage D, Marschke M, Plummer R: Adaptive co-management and the paradox of learning. Global Environmental Change 2008, 18(1):86-98.

12. Soklaridis S, Ravitz P, Adler Nevo G, Lieff S: Relationship-centred care in health: A 20-year scoping review. Patient Experience Journal 2016, 3(1):130-145.

13. Lichtenstein BB, Uhl-Bien M, Marion R, Seers A, Orton JD, Schreiber C: Complexity leadership theory: An interactive perspective on leading in complex adaptive systems. Emergence: Complexity \& Organization 2006, 8(4):2-12.

14. Plsek PE, Greenhalgh T: Complexity science: The challenge of complexity in health care. BMJ: British Medical Journal 2001, 323(7313):625-628.

15. Uhl-Bien M, Arena M: Complexity leadership: Enabling people and organizations for adaptability. Organizational Dynamics 2017, 46:9-20.

16. March JG: Exploration and Exploitation in Organizational Learning. Organization Science 1991, 2(1):71-87.

17. Lave J, Wenger E: Situated learning: Legitimate Peripheral Participation. Cambridge: Cambridge University Press; 1991.

18. Brown JS, Duguid P: Organizational learning and communities-of-practice: Toward a unified view of working, learning, and innovation. Organization Science 1991, 2(1):40-57.

19. Cook SD, Yanow D: Culture and Organizational Learning. Journal of Management Inquiry 1993, 2(4):373-390. 
20. Nonaka I: A dynamic theory of organizational knowledge creation. Organization Science 1994, 5(1):14-37.

21. Foley TJ, Vale L: What role for learning health systems in quality improvement within healthcare providers? Learning Health Systems 2017, 1(4):e10025.

22. McGinnis JM, Stuckhardt L, Saunders R, Smith M: Best care at lower cost: the path to continuously learning health care in America: National Academies Press; 2013.

23. Prange C: Organizational Learning - Desperately Seeking Theory? In: Organizational Learning and the Learning Organization: Developments in theory and practice. edn. Edited by Easterby-Smith M, Araujo L, Burgoyne J. London, UK: Sage; 1999: 24-43.

24. Huysman M: Balancing Biases: A Critical Review of the LIterature on Organizational Learning. In: Organizational Learning and the Learning Organization: Developments in theory and practice. edn. Edited by Easterby-Smith M, Araujo L, Burgoyne J. London, UK: Sage; 1999: 59-74.

25. Easterby-Smith M, Araujo L: Organizational Learning: Current Debates and Opportunities. In: Organizational Learning and the Learning Organization: Developments in theory and practice. edn. Edited by Easterby-Smith M, Araujo L, Burgoyne J. London, UK: Sage; 1999: 1-22.

26. Tosey P, Visser M, Saunders MN: The origins and conceptualizations of 'triple-loop' learning: A critical review. Management Learning 2012, 43(3):291-307.

27. Easterby-Smith M: Disciplines of Organizational Learning: Contributions and Critiques. Human Relations 1997, 50(9):1085-1113.

28. Argyris C, Schön D: Organizational Learning: A Theory of Action Perspective. Menlo Park, CA: Addison-Wesley; 1978.

29. Argyris C, Schön D: Organizational Learning II: Theory, method and practice. Reading, MA: AddisonWesley; 1996.

30. Huber GP: Organizational learning: The contributing processes and the literatures. Organization Science 1991, 2(1):88-115.

31. Wenger E: Communities of Practice: Learning, Meaning, and Identity. New York, NY: Cambridge University Press; 1999.

32. Reed M, Evely AC, Cundill G, Fazey IRA, Glass J, Laing A, Newig J, Parrish B, Prell C, Raymond C: What is Social Learning? Ecology and Society 2010:r1-r10.

33. Mezirow J: Transformative Dimensions of Adult Learning. San Francisco, CA: Jossey-Bass; 1991.

34. Yorks L, Marsick VJ: Organizational Learning and Transformation. Learning as Transformation 2000:253-281.

35. Senge PM: The Fifth Discpline: The Art \& Practice of the Learning Organization. New York, NT: Doubleday/Currency; 1990.

36. Burgoyne J, Pedler M, Boydell T: The Learning Company: A Strategy for Sustainable Development. London, UK: McGraw-Hill; 1991. 
37. Thomas K, Allen S: The Learning Organisation: A Meta-analysis of Themes in Literature. The Learning Organization 2006, 13(2):123-139.

38. Örtenblad A: On differences between organizational learning and learning organization. The Learning Organization 2001, 8(3):125-133.

39. Yeo RK: Revisiting the roots of learning organization: A synthesis of the learning organization literature. The Learning Organization 2005, 12(4):368-382.

40. Örtenblad A: What does "learning organization" mean? The Learning Organization 2018, 25(3):150158.

41. Easterby-Smith M, Lyles MA: Handbook of Organizational Learning and Knowledge Management. Oxford, UK: John Wiley \& Sons; 2011.

42. The Joanna Briggs Institute: Joanna Briggs Institute Reviewers' Manual: 2015 edition/supplement. In. Adelaide, AU: The Joanna Briggs Institute; 2015.

43. Arksey H, O'Malley L: Scoping studies: towards a methodological framework. International Journal of Social Research Methodology 2005, 8(1):19-32.

44. Levac D, Colquhoun H, O'Brien KK: Scoping studies: advancing the methodology. Implementation Science 2010, 5(1):69.

45. Tricco AC, Lillie E, Zarin W, O'Brien KK, Colquhoun H, Levac D, Moher D, Peters MD, Horsley T, Weeks L: PRISMA extension for scoping reviews (PRISMA-ScR): checklist and explanation. Annals of Internal Medicine 2018, 169(7):467-473.

46. Ulrichsweb.com ${ }^{\mathrm{Tm}}$ : Ulrichsweb Global Serials Directory. In.: ProQuest LLC; 2019.

47. Bramer WM, Giustini D, de Jonge GB, Holland L, Bekhuis T: De-duplication of database search results for systematic reviews in EndNote. Journal of the Medical Library Association: JMLA 2016, 104(3):240.

48. Ouzzani M, Hammady H, Fedorowicz Z, Elmagarmid A: Rayyan-a web and mobile app for systematic reviews. Systematic Reviews 2016, 5(1):210.

49. Easterby-Smith M, Snell R, Gherardi S: Organizational learning: diverging communities of practice? Management Learning 1998, 29(3):259-272.

50. Patton MQ: Qualitative Research and Evaluation Methods. Thousand Oaks, CA: Sage Publications, Inc.; 2002.

51. Chang W: The joint effects of customer participation in various new product development stages. European Management Journal 2019, 37(3):259-268.

52. Curado $C$, Oliveira $M$, Antunes M: Organizational ambidexterity and customer relationship management: A cycle of virtue. Knowledge and Process Management 2019, 26(3):229-243.

53. Jaziri D: The advent of customer experiential knowledge management approach (CEKM): The integration of offline \& online experiential knowledge. Journal of Business Research 2019, 94:241256. 
54. Ziyae B, Rezvani M, Zareai F: Explaining the Entrepreneurial Effect of Customer Knowledge Management on Product Innovation of Electronic Businesses. Journal of Organisational Studies \& Innovation 2019, 6(3):12-24.

55. Lundmark C, Jonsson G: Prospects for Learning in River Management: Exploring the Initial Implementation of the Water Framework Directive in a Swedish River Basin. Environmental Education Research 2014, 20(2):161-176.

56. Nonaka, Toyama R, Konno N: SECl, Ba and leadership: a unified model of dynamic knowledge creation. Long Range Planning 2000, 33(1):5-34.

57. Psek WA, Stametz RA, Bailey-Davis LD, Davis D, Darer J, Faucett WA, Henninger DL, Sellers DC, Gerrity G: Operationalizing the learning health care system in an integrated delivery system. EGEMS (Washington, DC) 2015, 3(1):1122.

58. Egunyu F, Reed MG, Sinclair JA: Learning Through New Approaches to Forest Governance: Evidence from Harrop-Procter Community Forest, Canada. Environmental Management 2016, 57(4):784-797.

59. Key KD, Lewis EY: Sustainable community engagement in a constantly changing health system. Learning Health Systems 2017, 2(3):e10053.

60. Teare GF, Keller M, Hall D: Bringing Together Research and Quality Improvement: The Saskatchewan Approach. Healthcare Quarterly 2018, 21:56-60.

61. Murphy S, Patlak M: A Foundation for Evidence-Driven Practice: A Rapid Learning System for Cancer Care: Workshop Summary. Washington, DC: The National Academies Press; 2010.

62. Olsen L, Aisner D, McGinnis JM: The Learning Healthcare System: Workshop Summary. Washington, DC: The National Academies Press; 2007.

63. McGinnis JM, Saunders RS, Olsen L: Patients Charting the Course: Citizen Engagement and the Learning Health System: Workshop Summary. Washington, DC: The National Academies Press; 2011.

64. Reid B, Hickman P: Are Housing Organisations becoming Learning Organisations? Some Lessons from the Management of Tenant Participation. Housing Studies 2002, 17(6):895.

65. Shipton H, Zhou Q, Mooi E: Is there a global model of learning organizations? An empirical, crossnation study. International Journal of Human Resource Management 2013, 24(12):2278-2298.

66. Garvin D: Building a Learning Organization. Harvard Business Review 1993, 71(4):78-91.

67. Marquardt $\mathrm{MJ}$ : Building the Learning Organization: A systems approach to quantum improvement and global success. New York, NY: McGraw-Hill 1996.

68. Cohen WM, Levinthal DA: Absorptive capacity: A new perspective on learning and innovation. Administrative Science Quarterly 1990, 35(1):128-152.

69. Polanyi M: The Tacit Dimension (2009 ed.). London, UK: University of Chicago Press; 1966.

70. Polanyi M: The Study of Man. London, UK: Routledge; 1958.

71. Cyert RM, March JG: A Behavioral Theory of the Firm. Englewood Cliffs, NJ: Prentice-Hall; 1963.

72. Levitt B, March JG: Organizational learning. Annual Review of Sociology 1988, 14(1):319-338. 
73. Bess KD, Perkins DD, Cooper DG, Jones DL: A heuristic framework for understanding the role of participatory decision making in community-based non-profits. American journal of community psychology 2011, 47(3):236-252.

74. Russell AJM: Understanding the nature of "success": An analysis of fisheries co-management regimes on Lake Malawi. Dissertation Abstracts International: Section B: The Sciences and Engineering 2007, 68(5):2726.

75. Brockman BK, Park JE, Morgan RM: The Role of Buyer Trust in Outsourced CRM: Its Influence on Organizational Learning and Performance. Journal of Business-to-Business Marketing 2017, 24(3):201-219.

76. Hafkesbrink J, Schroll M: Innovation 3.0: Embedding into Community Knowledge - Collaborative Organizational Learning Beyond Open Innovation. Journal of Innovation Economics \& Management 2011(7):55-92.

77. Kelsey E: Integrating multiple knowledge systems into environmental decision-making: Two case studies of participatory biodiversity initiatives in Canada and their implications for conceptions of education and public involvement. Environmental Values 2003, 12(3):381-396.

78. Yanow D: Translating local knowledge at organizational peripheries. British Journal of Management 2004, 15:S9-S25.

79. Diduck A, Sinclair AJ, Hostetler G, Fitzpatrick P: Transformative learning theory, public involvement, and natural resource and environmental management. Journal of Environmental Planning and Management 2012, 55(10):1311-1330.

80. Desai VM: Collaborative Stakeholder Engagement: An integration between theories of organizational legitimacy and learning. Academy of Management Journal 2018, 61(1):220-244.

81. Jarvis SV, Shear L: Community youth development: learning the new story. Child Welfare 1997, 76(5):719-741.

82. Veronesi G, Keasey K: Patient and Public Participation in the English NHS: An assessment of experimental implementation processes. Public Management Review 2015, 17(4):543-564.

83. Yu L, Jing S: Modeling of Knowledge Sharing between Organization and its Customers; 2008.

84. Dahiyat SE, Al-Zu'bi ZbMF: The Role of Knowledge Acquisition in Facilitating Customer Involvement in Product Development: Examining the Mediation Effect of Absorptive Capacity. International Journal of Learning and Change 2012, 6(3):171-206.

85. Ochocka J, Nelson G, Lord J: Organizational change towards the empowerment-community integration paradigm in community mental health. Canadian journal of community mental health = Revue canadienne de sante mentale communautaire 1999, 18(2):59-72.

86. Ryan WM: University-Community Partnerships as Learning Organizations - A Case Study. 2018.

87. Liu SS, Yuh-Yun Lin C: Building customer capital through knowledge management processes in the health care context. Health Care Management Review 2007, 32(2):92-101. 
88. Wang $X, X u M$ : Examining the linkage among open innovation, customer knowledge management and radical innovation: The multiple mediating effects of organizational learning ability. Baltic Journal of Management 2018, 13(3):368-389.

89. Mitchell HJ: The innovation link between organisation knowledge and customer knowledge. Hershey, PA: Idea Group Publishing; 2002.

90. Smith V: Becoming a Learning Organization in the Financial Industry: A Case Study. 2018.

91. Kass NE, Faden RR: Ethics and Learning Health Care: The Essential roles of engagement, transparency, and accountability. 2018, 2(4):e10066.

92. Lowes LP, Noritz GH, Newmeyer A, Embi PJ, Yin H, Smoyer WE, Tidball A, Love L, Schmidt J, Golias J et al: 'Learn From Every Patient': implementation and early results of a learning health system. Developmental Medicine and Child Neurology 2017, 59(2):183-191.

93. Campbell AJ: Creating customer knowledge competence: managing customer relationship management programs strategically. Industrial Marketing Management 2003, 32(5):375-383.

94. Cegarra-Navarro JG, Dewhurst F: Linking organizational learning and customer capital through an ambidexterity context: an empirical investigation in SMEs. International Journal of Human Resource Management 2007, 18(10):1720-1735.

95. Honig MI: Building policy from practice: District central office administrators' roles and capacity for implementing collaborative education policy. Educational Administration Quarterly 2003, 39(3):292338.

96. Battour M, Battor M: Can organizational learning foster customer relationships? Implications for performance. The Learning Organization 2013, 20(4):279-290.

97. Lavis JN, Gauvin F-P, Reid R, Bullock H, Wodchis WP, Hayes A: Rapid Synthesis: Creating a Rapidlearning Health System in Ontario. In. Hamilton, Canada: McMaster Health Forum; 2018.

98. Reay WE: Organizational adaptation: Bridging the research to practice gap. Administration and Policy in Mental Health and Mental Health Services Research 2010, 37(1):95-99.

99. Li Z, Wang D, Ma X: An Empirical Study of Organizational Learning's Influences on Customer Knowledge Acquirement Ability. In: 2012 Fifth International Conference on Business Intelligence and Financial Engineering. Lanzhou, China: IEEE Computer Society; 2012: 460-464.

100. Fojt M: Building a learning organization. Journal of European Industrial Training 1995, 19(6):3-4.

101. Lewin A, Massini S, Peeters C: Microfoundations of Internal and External Absorptive Capacity Routines. Organization Science 2011, 22(1):81-98.

102. Lewin A, Massini S: Knowledge creation and organizational capabilities of innovating and imitating firms. In: Organizations as Knowledge Systems: Knowledge, Learning and Dynamic Capabilities. edn. Edited by Tsoukas H, Mylonopoulous N. New York, NY: Palgrave/Macmillan; 2004: 209-237.

103. Ricciardi F, Cantino V, Rossignoli C: Organisational learning for the common good: an emerging model. Knowledge Management Research \& Practice 2020. 
104. Erkelens R, Hooff B, Huysman M, Vlaar P: Learning from Locally Embedded Knowledge: Facilitating Organizational Learning in Geographically Dispersed Settings. Global Strategy Journal 2015, 5(2):177-197.

105. Inkpen AC: Learning, knowledge management, and strategic alliances: so many studies, so many unanswered questions. In: Cooperative Strategies and Alliances. edn. Edited by Contractor P, Lorange F. London, UK: Pergamon; 2002: 267-289.

106. Rowe R, Shepherd M: Public Participation in the New NHS: No Closer to Citizen Control? Social Policy \& Administration 2002, 36(3):275-290.

107. Feldberg G, Vipond R: The virus of consumerism. In: Health Reform: Public Success, Private Failure. edn. Edited by Drache D, Sullivan TJ. London, UK: Routledge; 1999: 448-464.

108. Martin GP: 'Ordinary people only': knowledge, representativeness, and the publics of public participation in healthcare. Sociology of Health \& IIIness 2007, 30(1):35-54.

109. Jacobs C, Coghlan D: Sound from silence: On listening in organizational learning. Human Relations 2005, 58(1):115-138.

110. Foucault M: The Order of Things: An Archeology of the Human Sciences. London, UK: Routledge; 2000.

111. Wildemeersch D, Jansen T, Vandenabeele J, Jans M: Social learning: A new perspective on learning in participatory systems. Studies in Continuing Education 1998, 20(2):251-265.

112. Fraser A, Baeza JI, Boaz A: 'Holding the line': a qualitative study of the role of evidence in early phase decision-making in the reconfiguration of stroke services in London. Health Research Policy and Systems 2017, 15(1):45.

113. Jones L, Exworthy M: Framing in policy processes: A case study from hospital planning in the National Health Service in England. Social Science \& Medicine 2015, 124:196-204.

114. Mezirow J: Learning to think like an adult: core concepts of transformation theory. In: Learning as transformation: Critical perspectives on a theory in progress. edn. Edited by Mezirow J. San Francisco, CA: Jossey-Bass; 2000: 3-24.

115. Lam A: The Social Embededness of Knowledge: Problems of Knowledge Sharing and Organisational Learning in International High-Technology Ventures. In: DRUID Working Paper No 98-7. Aalborg, DK: DRUID, Copenhagen Business School, Aalborg University; 1998.

116. Caffrey L, Ferlie E, McKevitt C: The strange resilience of new public management: the case of medical research in the UK's national health service. Public Management Review 2019, 21(4):537558.

117. Bevan G, Hood C: What's measured is what matters: targets and gaming in the English public health care system. Public Administration 2006, 84(3):517-538.

118. Weinfurt KP, Lin L, Sugarman J: Public views regarding the responsibility of patients, clinicians, and institutions to participate in research in the United States. Clinical Trials 2019, 16(6):574-579. 
119. Dosi G, Nelson R, Winter S: The Nature and Dynamics of Organizational Capabilities. Oxford, UK: Oxford University Press; 2000.

120. Merriam SB, Caffarella RS, Baumgartner LM: Learning in adulthood: A comprehensive guide, 3rd edn. San Francisco, CA: John Wiley \& Sons; 2007.

121. Young IM: Difference as a resource for democratic communication. Deliberative democracy: Essays on reason and politics 1997, 383-406.

\section{Figures}

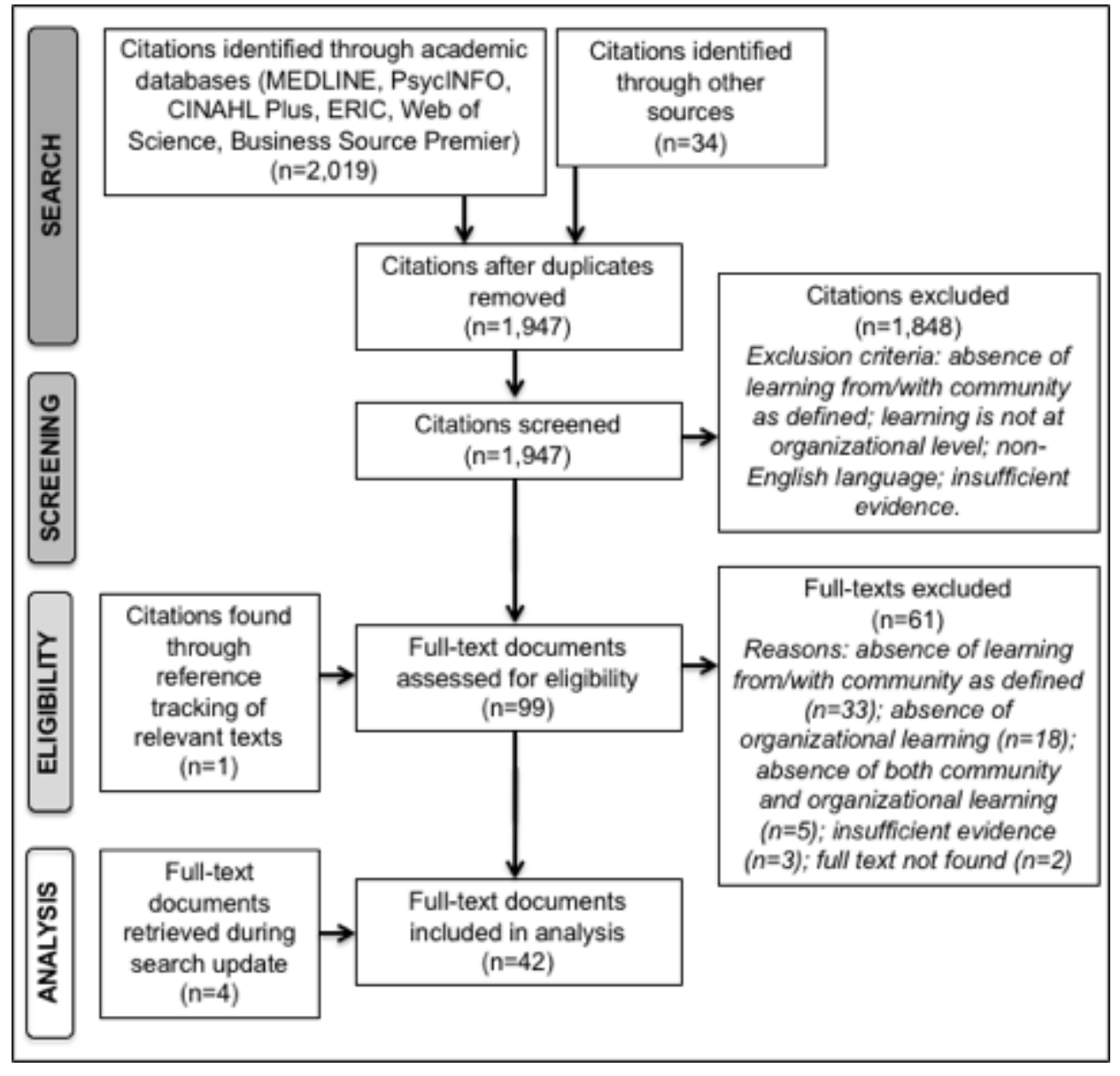

\section{Figure 1}

Flow chart of study selection 


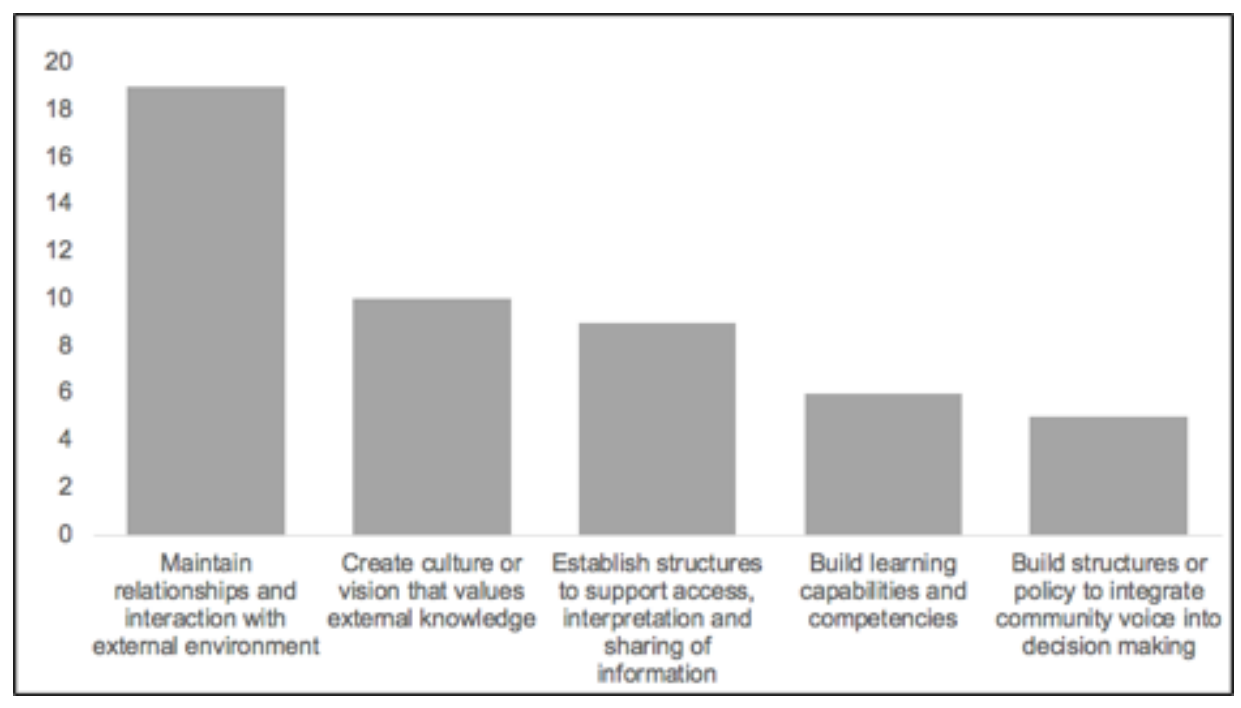

Figure 2

Strategies to support organizational learning from or with community, by number of citing texts

\section{Supplementary Files}

This is a list of supplementary files associated with this preprint. Click to download.

- AdditionalFile1.SampleSearchStrategy.docx

- AdditionalFile2.DataCharting.docx

- AdditionalFile3.PRISMASCRchecklist.pdf 